\title{
Chemical Composition Variation in Wild and Cultivated Albanian Salvia Officinalis L. Essential Oil
}

\author{
Evelina Hasa $^{1 *}$, Sonila Duka², Sidita Mance ${ }^{3}$, Enida Nushi ${ }^{4}$ \\ 1,2,3 Tirana University, Faculty of Natural Sciences, Chemistry Department; \\ ${ }^{4}$ Noval Laboratory shpk, Koxhas, Maminas, Durres
}

\begin{abstract}
This study aims to see if different patterns of chemical composition from wild and cultivated Salvia Officinalis $L$. chemo types are obtained. Ten representative samples were taken in different locations. They were collected from a large number of plants, representing the population of the sampling stations, during the flowering stage, June. Essential oils were analysed, using GC-FID and GC MS/MS. Both wild and cultivated ecotypes preserve Salvia Officinalis $L$. species characteristics, relating to chemical composition patterns, but show differences in individual chemical compounds content. Sage originating from imported seed cultivated in north resulted richer in camphor (32.02\%). Sage originating from wild Albanian seeds, cultivated in north-west preserved the north ecotype and, resulted richer in $\alpha$-thujone $(41.34 \%)$. a-thujone in wild sage of north and north-west, resulted, from $32.88 \%$ to $46.64 \%$, and camphor, $14.39 \%$ to $19.53 \%$ (Bardhoc/M4 \& Hani I Hotit/M1). Environmental factors seem to have no influence in this case. Cultivated sage plants, originating from plant cutting of wild Albanian ecotype sage, preserve the typical pattern of chemical content and composition for the respective locations, they were cultivated. In north (Koplik/M2), both cultivated and wild resulted rich in a-thujone, 34.62\%, and 37.32\%. In south (Gjirokaster/M8 \& Dragot/M9), cultivated and wild resulted rich in camphor, varying from $24.31 \%-29.34 \%$ and $39.47 \%$ $41.38 \%$ respectively, inheriting the same chemo type of wild indigenous populations. Cultivated sage plants, originating from wild Albanian ecotypes, preserve the essential oil composition pattern, even in different geographic positions. Seeds genetic background seems to be a factor impacting essential oil composition patterns. This factor could be used for selection and cultivation purposes.
\end{abstract}

Key words: cultivated; ecotype; sage; seed, genetic 


\section{$5^{\text {th }}$ International Conference On Applied Research In SCIENCE, TECHNOLOGY \& KNOWLEDGE}

26-28 February, 2021

Amsterdam, Netherlands

\section{Introduction}

Salvia officinalis $L$. belongs to the Lamiaceae family, a medicinal and aromatic plant species indigenous to the South-European Balkan Peninsula and the Adriatic islands. Frequently is collected from natural sites in these areas and exported as dry leaves as compared with other Mediterranean countries in which the plant is cultivated (Zutic et al., 2003). In Albania, over $90 \%$ of the medicinal and aromatic plants are grown and collected from the wild. They are processed in the country and exported as dried plants, essential oils, and fresh aromatic sachets (FAO/TRAFFIC. 2010, Bazina, 2012). Being one of the most important medicinal and aromatic plants S. Officinalis L. has a great economic and industrial value. Albania is an important exporter of medicinal and aromatic plants in Europe and the most important exporter of sage to the USA (Asllani, 2004, Karaj et al., 2017). Salvia officinalis L. is rich in essential oil, which accounts for part of their bioactive and aromatic qualities (Boelens \& Boelens, 1997). Forms of the plant commonly used by the food industry, are leaves, essential oils (EO), and oleoresins. They are an important source of many bioactive constituents including terpenes and flavonoids, such as monoterpenes like $\alpha$ - and $\beta$-thujone, 1, 8-cineole, camphor, etc., used mostly as antimicrobial agents (Cvetkovikj et al., 2013 A), (Cvetkovikj et al., 2015 B), Giannouli \& Kintzios, 2008, Stefkov, 2011). Different studies show that differences of a distinct compound in the essential oils between individuals are so big, that they form distinct chemical entities (chemo types). In the essential oil of S. officinalis chemo types are rather frequent, about 18 essential oil chemo types have been described so far (Jug-Dujakovic et al., 2012, Lamien-Meda et al., 2010, Novak et al., 2006, Perry et al., 1996). According to JugDujakovic et al., 2012, essential oil composition of different populations of Salvia officinalis $L$. are mostly genetically controlled, emphasizing this as an important factor. Still, there are other factors such as variation among different plant parts, their different stages of development, and modifications due to the environment (Franz, 1993). According to E. Bazina, 2015 "in situ" cultivation of S. Officinalis L. arises as a need due to market demand for Albanian wild sage and inappropriate harvesting practices. Sage can be propagated vegetatively by terminal cuttings and generatively by nutlets (referred to as seed) (Zutic \& Dudai, 2008). Cultivation conditions weren't the scope of the present study, the aim of it was to see if there are differences in essential oil chemical composition pattern between Albanian sage, from different origins such as seeds and plant cuttings, grown up under cultivation conditions and wild Albanian local sage. The information can be used to locate it in the right direction depending on the market needs and different forms of use such as breeding or cultivation of the plant itself.

\section{Materials and method}

\subsection{Plant material}

Sampling was concentrated on five different geographic locations of Albania, from the north, (Hani I Hotit/M1, Koplik/M2), north-east (Bardhoc/M4) to the south (Gjiorkaster/M8, Dragot/M9) during flowering stage June 2017 one of the main harvesting season for S.officinalis L. At each location, plant samples were collected randomly, from a large number 
of plants, representing the population of the sampling station. For each location two representative samples were taken, wild and under cultivated conditions. Cultivated sage was collected on five different land plots on the locations mentioned above, planted by area farmers in an approximately $250 \mathrm{~m}$ to $483 \mathrm{~m}$ distance from the wild sage location. The selection of cultivated plants was made taking into account different origins such as seed (imported and those from wild Albanian ecotype), plant cutting from wild Albanian ecotypes which were grown up under cultivation conditions. North and north-east Albania represent the same ecotype of Salvia Officinalis L. (Asllani, 2000). Sage plants obtained from imported seeds were collected in Hani I Hotit/M1 location, those from wild Albanian populations seeds were collected in Bardhoc/M4 location. In the same region of northern Albania, sage plants originating from plant cutting of wild Albanian ecotypes were collected in Koplik/M2. As per south Albania, two sampling points were chosen Dragot/M9 and Gjirokaster/M8, where sage plants originating from plant cutting of wild Albanian ecotypes were collected. At each of the mentioned locations wild local Albanian sage was collected too in altitudes from 500 to $800 \mathrm{~m}$ above sea level. Part of the plant chosen to be analysed were aerial parts (leaves). Samples were collected by hand, taking into account "Good collection practice of medical and aromatic plants in nature" and were placed in airy places, in shade to get fully dried at room temperature, then packed in paper bags and kept in a dark and cold place until analysis.

\subsection{Oil extraction}

Dry leaves were cleaned from impurities and all other solid matters or other plants. Samples were comminuted before hydro distillation extraction. Plant/liquid ratio used was 1:10 (g:ml). The quantity of sample used is $50 \mathrm{~g}$ immersed in $500 \mathrm{ml}$ water, using a distillation flask heater and a Clevenger-type apparatus for 3 hours, at boiling point temperature. The obtained essential oils were dried with anhydrous sodium sulphate and stored at $4-5{ }^{\circ} \mathrm{C}$ for further analysis. All samples were used for oil profiling with GC-FID/GC-MS/MS analysis and all of them, were chosen to compare essential oil composition differences. Samples were analysed at Noval Laboratory shpk, a laboratory in Maminas, Durres, Albania. Analysis of the essential oil was carried out in SHIMADZU NEXIS GC-2030 (Shimadzu Europa GmbH, Analytical and Measuring Instruments) chromatograph with a data handling software Lab solution, equipped with a Split/Split less injector SPL 2030, On-Column injection unit OCI 2030, and Flame ionization detectors (FID-2030). Agilent 7000D triple quadrupole GC/MS (Agilent). Essential oils fraction was carried out with an Agilent GC/MSD system with a mass spectrometer detector 7000D MS, 7890B GC, and Mass Hunter acquisition, data handling, and reporting software. Highly inert capillary column Rxi-5ms column Rxi-5ms, (30m x 0.25mm, film thickness $0.50 \mu \mathrm{m}), \mathrm{ID}, 0.25 \mathrm{~mm}$, was used. $10 \mu \mathrm{l}$ of essential oil, was accurately weighed in a vial and $1000 \mu \mathrm{l}$ of Hexane. Temperature program of the column: $60^{\circ} \mathrm{C}$ for $1 \mathrm{~min}, 4 \mathrm{oC} / 1$ min till $180{ }^{\circ} \mathrm{C}$ and $20 \mathrm{oC} / 1 \mathrm{~min}$ till $250{ }^{\circ} \mathrm{C}$, total $40 \mathrm{~min}$. A carrier gas, Helium, column flow $1 \mathrm{ml} / \mathrm{min}$ constant speed, total flow $14 \mathrm{ml} / \mathrm{min}$ split ratio 100:1. Injection volume $1 \mu \mathrm{L}(10 \mu \mathrm{L}$ syringe). Chemical components, identification was made by the comparison of their relative retention time and mass spectra with those of compounds published in literature and databases. The identified components were listed according to their retention time. 
Percentage composition of chemical components was calculated according to their chromatographic peak area.

\section{Results and discussion}

Chemical composition of Salvia Officinalis L. essential oil samples are showed in (Table 1). Thirty compounds were identified in essential oils, from which we extracted those with the highest percentage and at the same time, typical of sage essential oil. Chromatograms show that all samples from different origins were all rich in $\alpha$-thujone, camphor, $\beta$-thujone, camphene, ledol, 1, 8 cineol, and $\beta$-pinene and none of the chemical compounds identified were found to miss or not be detected in all samples. Results obtained are fully in accordance with Asllani, 2000, relating chemical composition of the essential oils, showing the same characteristics of S. officinalis L. specie. Interesting variations have been noticed between wild ecotype and cultivated.

Table 1: Yield (\%) and chemical composition of Salvia officinalis L. essential oil cropped in different locations, and from different origins

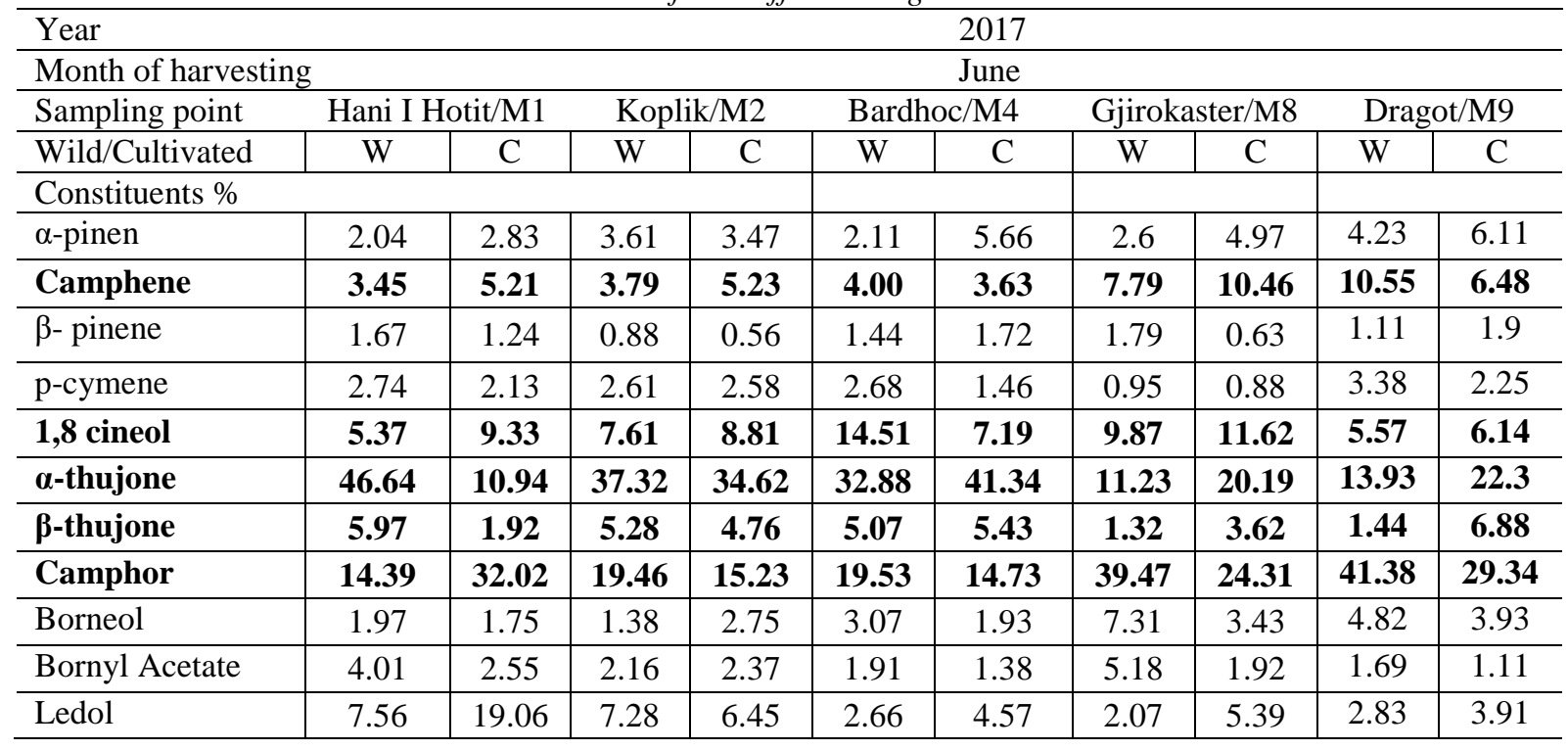

The biggest difference was noted between wild sage and the one that originated from imported seed cultivated in Hani I Hotit/M1 location. Wilde sage was found to be rich in $\alpha$-thujone, $46.64 \%$ and camphor $14.39 \%$ also other components with less percentage such as $\beta$-thujone $5.97 \%$, camphene $3.45 \%, 1,8$ cineol $5.37 \%$, ledol $7.56 \%$. Cultivated sage originating from imported seeds and collected in the same location but at a certain distance (the plot where was cultivated) from the point where the wild sage was collected, shows a totally different pattern relating to chemical compounds content. It was found to be rich in camphor $32.02 \%$ and less in $\alpha$-thujone $10.94 \%$, compared to wild populations. The result obtained was atypical for north type sage. The same comparison was done between wild sage and cultivated plants, but in this case, originating from wild Albanian ecotype seeds. Samples were collected both in Bardhoc/M4. 


\section{$5^{\text {th }}$ International Conference On Applied Research In SCIENCE, TECHNOLOGY \& KNOWLEDGE}

The chemical content and composition of these samples, preserve the typical north type sage pattern. Both wild and, cultivated resulted to be rich in $\alpha$-thujone, $32.88 \%$, and $41.34 \%$ respectively, and camphor also $19.53 \%$ and $14.73 \%$. They preserve the inverse relationship between $\alpha$-thujone and camphor. Another similar inverse relationship noticed was the one between $\alpha$-thujone and both camphene and 1, 8 cineol, when one rises the other decreases. Cultivated sage, originating from wild Albanian ecotype seeds show higher content of $\alpha$ thujone than wild, this means less camphor, camphene, and 1, 8 cineol. The comparison between two different seeds origin where environmental elements, such as soil texture or climate conditions are a common factor, shows that different essential oil patterns are obtained, highlighting that the essential oil composition, is under genetic control (Putievsky et al., 1992).

Figure 1: Variation of $\alpha$-thujone and camphor in wild and cultivated ecotypes
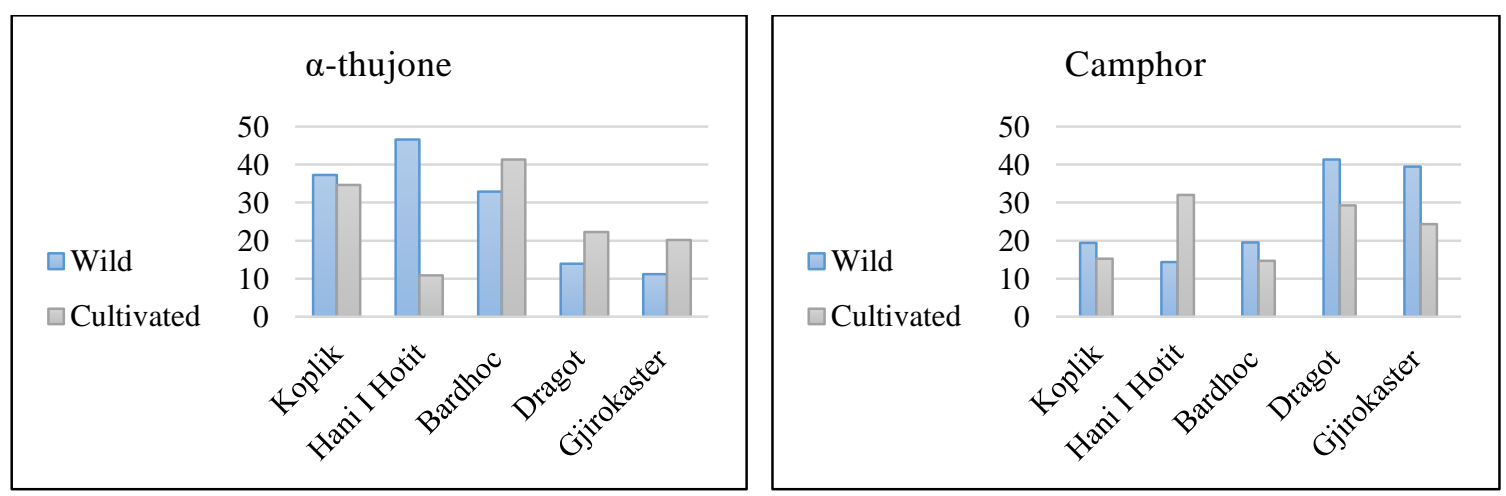

Sage plants cultivated in Koplik/M2, Dragot/M9 and Gjirokaster/M8, originating from plant cutting of wild Albanian ecotypes, preserve the typical sage pattern relating chemical content and composition of the respective locations where they were collected. Cultivated north sage (Koplik/M2), found to be rich in $\alpha$-thujone $34.62 \%$ and less in camphor $15.23 \%$. Wild sage collected in the same area show higher content of $\alpha$-thujone $37.32 \%$ than cultivated. To be mentioned is that in cultivated sage, the content of camphor, camphene, and 1,8 cineol seems to be higher than the wild ecotype. The same line was noted for samples cultivated in the south (Dragot/M9 and Gjirokaster/M8), originating from plant cutting of wild Albanian ecotypes. They preserve the typical camphor type of south sage, just as wild ecotype. In Dragot and Gjirokaster, camphor is the main component with the highest content, $29.34 \%$ and $24.31 \%$ respectively. Wild ecotypes, for the same locations show higher content of camphor, in Dragot 41.38\% and Gjirokaster 39.47\%. E. Bazina, 2015, in her study noticed, the differences that come between plants originating from and cultivated in the same eco-zone of wild ecotypes. She explained that some factors like age and developmental stage of the mother plants and variability within the same plant population may affect the results obtained. 
Figure 2: Variation of $\alpha$-thujone and camphor in wild and cultivated ecotypes from different origin,

a) wild ecotype sage and cultivated originated from imported seed and from wild Albanian ecotype seeds

b) wild ecotype sage and cultivated originated from wild Albanian ecotype seeds and from plant cutting of wild Albanian ecotypes

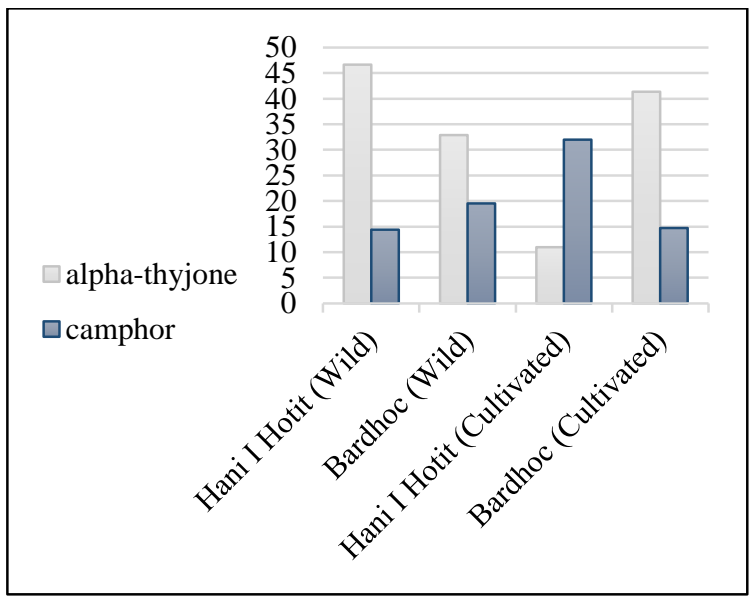

a)

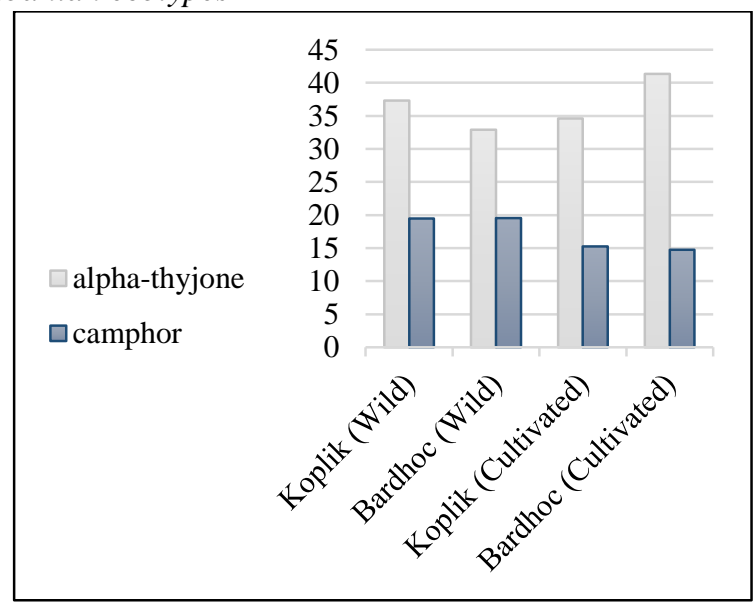

b)

\section{Conclusions}

$\checkmark \quad$ In this study all samples analysed despite different origin (cultivated or wild), were all rich in $\alpha$-thujone, camphor, ledol, 1, 8 cineol, $\beta$-thujone, camphene, and $\beta$-pinene.

$\checkmark$ Sage originating from imported and wild Albanian ecotype seeds, cultivated in the same region with similar environmental conditions, gives different essential oil pattern relating to the main components content.

$\checkmark$ Sage originating from imported seed cultivated in north resulted richer in camphor than in $\alpha$-thujone, atypical for north chemo type. Instead sage originating from wild Albanian seeds, preserved the north chemo type, richer in $\alpha$-thujone. Indigenous ecotype seeds cultivated seems to preserve, Albanian wild essential oil profile.

$\checkmark$ Originating from plant cutting of wild Albanian ecotype sage, preserve the typical pattern relating to chemical content and composition of the respective locations where they were cultivated, inheriting the same chemo type of wild indigenous populations.

$\checkmark$ Plant cutting of wild Albanian ecotype sage, cultivated in north, resulted rich in $\alpha$ thujone and those from south rich in camphor. The diversity of chemo types gives multiple selection options for cultivation.

$\checkmark$ Cultivated sage plants, originating from wild Albanian ecotypes due to similarity of their chemical composition profiles to wild indigenous sage, it is recommended to be used for breeding or cultivation purpose.

$\checkmark$ This study results are indicative because more in-depth investigations into many other factors need to be taken in consideration, where among these are plant cultivation conditions but as mentioned aren't part of this study.

$\checkmark$ Seeds' genetic background seems to be a factor impacting essential oil composition patterns. 


\section{$5^{\text {th }}$ International Conference On Applied Research In SCIENCE, TECHNOLOGY \& KNOWLEDGE}

26-28 February, 2021

Amsterdam, Netherlands

\section{References}

[1] Zutic, I., Putievsky, E. and Dudai, N. (2003). "Influence of harvest dynamics and cut height on yield components of sage (Salvia officinalis)," Journal of Herbs, Spices and Medicinal Plants vol. 10(4), pp 49-61.

[2] FAO/TRAFFIC. 2010. Expert Consultation on Institutional Needs for Sustainable Non-Wood Forest Product Sector in Southeast Europe; Country Presentation, Albania; Bazina, E.Available:http://www.fao.org/regional/SEUR/events/sarajevo/sarajevo_en.htm.

[3] Bazina, E. (2012). "Enabling Sustainable Management of Non-Wood Forest Products in Southeast Europe-Albania's Experience.” Journal of life Sciences 6 (12): 1391-5.

[4] Asllani, U., (2004), "The essential oils of Medicinal and Aromatic Plants from Albania”, ILAR, Tirana, Albania.

[5] Karaj, S., Gruda, N., Ibraliu, A., Müller, J. (2017). "Medicinal and Spice Plants in Albania", J. Med. Spice Plants (Zeitschrift fur Arznei-\& Gewurzpflanzen), vol. 22, pp. 66-68.

[6] Boelens, M.H., Boelens, H., (1997), "Chemical and sensory evaluation of three sage oils", Perfum. Flavor, vol. 22, pp. 19-40.

[7] Cvetkovikj, I., Stefkov, G., Acevska, J., Stanoeva, J. P., Karapandzova, M., Stefova, M., (2013), "Polyphenolic characterization and chromatographic methods for fast assessment of culinary Salvia species from South East Europe”, Journal of Chromatography A, vol. 1282, pp. 38-45.

[8] Cvetkovikj, I., Stefkov, G., Karapandzova, M., Kulevanova, S., \& Satovic, Z. (2015), "Essential oils and chemical diversity of South-East European populations of Salvia officinalis L.", Chemistry \& Biodiversity, vol. 12, pp. 1-16.

[9] Giannouli, A. L., \& Kintzios, S. E. (2008), "Essential oils of Salvia spr: examples of intraspecific and seasonal variation. In S. E. Kintzios (Ed.), SAGE "The Genus Salvia", Harwood Academic Publishers, pp. 69-79.

[10] Stefkov, G., Cvetkovikj, I., Karapandzova, M., \& Kulevanova, S. (2011), "Essential oil composition of wild growing Sage from R. Macedonia", Macedonian Pharmaceutical Bulletin, vol. 57, pp. 71-76.

[11] Jug-Dujakovic, M., Ristic, M., Pljevljakusic, D., Dajic-Stevanovic, Z., Liber, Z., Hancevic, K., Radic, T., Satovic, Z., (2012), "High diversity of indigenous populations of dalmatian sage (Salvia officinalis L.) in essential-oil composition," Chem. Biodivers, vol.9, pp. 2309-2323. 


\section{$5^{\text {th }}$ International Conference On Applied Research In SCIENCE, TECHNOLOGY \& KNOWLEDGE}

[12] Lamien-Meda, A., Schmiderer, C., Lohwasser, U., Börner, A., Franz, C., Novak, J.,(2010). "Variability of the essential oil composition in the sage collection of the Genebank Gatersleben: a new viridiflorol chemotype", Flavour Fragr. Journal, vol. 25, pp. 75-82.

[13] Novak, J., Marn, M., Franz, C., (2006), “An a-pinene chemotype in Salvia officinalis L.," Journal Essent. Oil Res, vol. 18, pp. 239-241.

[14] Perry, N.B., Anderson, R.E., Brennan, N.J., Douglas, M.H., Heaney, A.J., McGimpsey, J.A., Smallfield, B.M., (1999), "Essential oils from Dalmatian sage (Salvia officinalis L.): variations among individuals, plant parts, seasons, and sites," Journal Agric. Food Chem, vol.47, pp. 2048-2054.

[15] Franz, C., (1993), Genetics. On: R. Hay, P. G. Waterman, "Volatile Oil Crops: Their Biology, Biochemistry and Production”, U.K.: Wiley, pp. 63-96.

[16] Bazina, E., (2015), "Chemical Variation in Essential Oils of Salvia Officinalis L. Ecotypes Cultivated in Albania," Journal of Life Sciences, vol. 9, pp. 95-102.

[17] Zutic, I., Dudai, N., (2008), "Factors Affecting Germination of Dalmatian Sage (Salvia officinalis) Seed", Proc. IVth IS on Seed, Transplant and Stand Establishment of Hort. Crops, Ed.: D.I. Leskovar Acta Hort. 782.

[18] Asllani, U. (2000), "Chemical Composition of Albanian Sage Oil (Salvia officinalis L.”, Journal Essent. Oil Res, vol. 12, pp. 79-84.

[19] Putievsky, E., Ravid, U., Sanderovich, D., (1992), "Morphological Observations and Essential Oils of Sage (Salvia officinalis L.) Under Cultivation", Journal Essent. Oil Res., vol. 4, pp. 291-293. 